\title{
Validating the use of baited remote underwater video surveys for assessing the diversity, distribution and abundance of sharks in the Bahamas
}

\author{
Edward J. Brooks ${ }^{1,2, *}$, Katherine A. Sloman ${ }^{3}$, David W. Sims ${ }^{2,4}$, Andy J. Danylchuk ${ }^{5}$ \\ ${ }^{1}$ Shark Research and Conservation Program, Cape Eleuthera Institute, Eleuthera, The Bahamas \\ ${ }^{2}$ School of Marine Science and Engineering, Marine Institute, University of Plymouth, Plymouth, UK \\ ${ }^{3}$ School of Science, University of the West of Scotland, Paisley, UK \\ ${ }^{4}$ Marine Biological Association of the United Kingdom, The Laboratory, Citadel Hill, Plymouth, UK \\ ${ }^{5}$ Department of Environmental Conservation, University of Massachusetts, Amherst, Massachusetts 01003, USA
}

\begin{abstract}
Baited remote underwater video surveys (BRUVS) are a novel, non-invasive method of generating relative abundance indices for a number of marine species, including sharks. This technique has become increasingly prevalent in shark ecology literature, but has yet to be formally validated against more traditional shark survey methods. BRUVS and longline surveys were conducted over 4 seasons from summer 2008 to spring 2009, in 3 habitat zones in the waters off Cape Eleuthera, The Bahamas. By the end of the project, both techniques generated similar values of species richness; however, longline surveys reached these values faster and with fewer replicates than BRUVS. Overall there was a significant positive correlation of relative abundance between the 2 survey techniques, but when analysed on a species-by-species basis, correlations were not statistically significant for the less abundant species. This suggests a threshold level of abundance, below which relative abundance estimates generated by the different survey techniques do not agree. In addition, this study identified shortcomings in the ability of BRUVS to accurately identify the species, size and sex of individuals captured on video due to the variable behaviour of the sharks in front of the camera; however, technological improvements incorporated into contemporary studies are identified which might improve data quality. BRUVS offer a non-invasive alternative to longline surveys for monitoring broad trends in the relative abundance of sharks, although in the format tested in this study they may lack the resolution required to approach finer scale, intra-species studies.
\end{abstract}

KEY WORDS: Baited remote underwater video surveys · Longline surveys • Catch per unit effort • Relative abundance $\cdot$ Carcharhinus perezi $\cdot$ Ginglymostoma cirratum

Resale or republication not permitted without written consent of the publisher

\section{INTRODUCTION}

Many shark populations worldwide are in rapid decline due to chronic overfishing and the slow reproductive life-history characteristics exhibited by most elasmobranchs (Stevens et al. 2000, Baum et al. 2003, Baum \& Myers 2004, Myers et al. 2007, Field et al. 2009). Fundamental ecological information pertaining to the diversity, distribution and abundance of sharks is vital for the development of effective management and conservation initiatives (Southwood \& Henderson 2000, Garla et al. 2006). However, for most species, even the most basic ecological information is lacking, which has led to $46 \%$ of sharks, skates and rays being listed as 'Data Deficient' on the IUCN Red List of Threatened Species (IUCN 2010).

The most common method of deriving basic ecological information from shark populations is through scientific longline surveys. These surveys generate relative abundance estimates which provide comparative 
estimates of abundance through space and time (Henderson 2003), on both inter- and intra-species levels (e.g. Pikitch et al. 2005). Longline relative abundance indices are derived from catch per unit effort (CPUE) calculations, and are usually expressed in sharks caught per hook per hour (sharks hook ${ }^{-1} \mathrm{~h}^{-1}$ ). Relative abundance estimates generated from scientific longline surveys have been utilised in a number of shark ecology studies, including those investigating declines in shark abundance (Simpfendorfer et al. 2002), habitat use and demographic population structure (Pikitch et al. 2005) and variation in seasonal abundance (Wirsing et al. 2006). In addition, the surveys themselves provide a vehicle for deploying numerous acoustic and satellite telemetry devices (Holland et al. 1999, Heithaus et al. 2007).

Despite their utility and widespread application, longline surveys for sharks do have significant drawbacks. Surveying requires the hooking, retrieval and restraint of subject animals, which in turn imposes various degrees of physical trauma and physiological stress, the magnitude of which is dependent on the capture method and handling time (Skomal 2006, 2007). These homeostatic disruptions can potentially impact growth, feeding and the immune system, and may also impede normal physiological and behavioural function, leading to population-level consequences (Cooke et al. 2002, Skomal 2006). If either physiological stress or physical trauma, or a combination of the two, is excessive, then immediate or delayed (post-release) mortality is possible (Skomal 2007). Given the rapid declines in many shark populations, this homeostatic disruption and associated mortality is contrary to conservation-based objectives of many shark research programmes.

One of the key benefits of longline surveys is their ability to quantify catch and effort in an easily replicable manner. Nevertheless, these benefits are also inherent to a number of different techniques that do not require the physical capture of sharks. Underwater imaging has been used to study the marine environment and its inhabitants for over 40 yr (Bailey et al. 2007). Deep-ocean research pioneered the use of this technology, and the first baited camera was developed in 1967 in California (Isaacs 1969). In more recent years, underwater video surveys have become more prevalent in the literature following the progress of video towards being a cheap and accessible medium (Shortis et al. 2009). Currently, baited remote underwater video surveys (BRUVS) have become the standard approach for larger-bodied, more cautious reef fish, including sharks (Meekan \& Cappo 2004, Meekan et al. 2006, Malcolm et al. 2007).

BRUVS provide a number of major benefits over traditional capture-based survey methods, the most fun- damental of which is that they are non-invasive, nondestructive and cause minimal damage to the benthic environment. They detect large, mobile animals that avoid divers and active fishing surveys (Cappo et al. $2004,2006)$, and all animals attracted to the vicinity of the bait are 'captured', independent of the effectiveness of the capture process (Armstrong et al. 1992). BRUVS are not size selective like many traditional methods, where hook or mesh size are only effective for a certain size range, and the standardised surveys can be replicated at any depth, in a variety of habitats, and by staff with relatively low levels of training (Cappo et al. 2006). A number of different relative abundance indices have been generated from BRUVS; these include time of first arrival (Priede \& Merrett 1996), maximum number of animals viewed on the videotape at any one time (Willis et al. 2000, Malcolm et al. 2007) and standard CPUE measured in sharks $\mathrm{h}^{-1}$ (Meekan \& Cappo 2004, Meekan et al. 2006). Maximum number has become the most common relative abundance index for studying reef fish assemblages where the animals surveyed are numerous and constantly entering and leaving the video (Cappo et al. 2006). For larger, less abundant species such as sharks, where individuals are more easily identified by species, sex and size, CPUE is the more common choice (e.g. Meekan \& Cappo 2004, Meekan et al. 2006).

The use of BRUVS to quantify shark abundance and diversity has become more commonplace in recent years for many of the reasons described above. In addition to generating datasets comparable to longline surveys, there are few to no negative impacts on the subject animals. To date, BRUVS have been used successfully to monitor sharks in Australia (Meekan \& Cappo 2004, Meekan et al. 2006), Florida (C. Simpfendorfer pers. comm.), the Cayman Islands (M. Gore pers. comm.) and Belize (D. Chapman pers. comm.). However, despite the increasing prevalence of this technique in the literature, there has been no attempt to formally quantify and validate the relative abundance indices it generates against more traditional survey techniques.

Baited video surveys have been validated against both prawn trawls (Cappo et al. 2004) and longline surveys (Ellis \& DeMartini 1995). The latter study concluded that baited video surveys can replicate the relative abundance indices generated by longline surveys for juvenile pink snapper Pristipomoides filamentosus; however, the equipment and protocols employed for both baited video and longline surveys are not comparable to contemporary shark survey techniques. Furthermore, the pink snapper is a relatively abundant teleost whose ecology and behavioural characteristics are very different from those of elasmobranchs. 
Given the lack of a rigorous validation of contemporary BRUVS, the objective of this study was to compare and validate the trends in shark diversity and relative abundance generated by BRUVS against traditional scientific longline surveys. In addition, this study compared the quality of the data generated, the degree of ecological impact and the cost effectiveness of the respective survey types.

\section{MATERIALS AND METHODS}

This study was conducted between 1 July 2008 and 1 July 2009 in the waters adjacent to Cape Eleuthera, Eleuthera, The Bahamas $\left(24.54^{\circ} \mathrm{N}, 76.12^{\circ} \mathrm{W}\right)$. All research was carried out under Cape Eleuthera Institute (CEI) research permits (MAF/FIS/17 and MAF/FIS/34) issued by the Bahamian Department of Marine Resources in accordance with CEI animal care protocols developed within the guidelines of the Association for the Study of Animal Behaviour and the Animal Behaviour Society (see Rollin \& Kessel 1998).

Study area and sampling structure. The island of Eleuthera is situated on the eastern edge of the Great Bahamas Bank, the largest of the 3 carbonate platforms which comprise the Bahamian archipelago (Buchan 2000). The Great Bahamas Bank is divided by 2 deepwater inlets of the Atlantic Ocean. The northeast corner of 1 of these inlets, the Exuma Sound, is located immediately adjacent to Cape Eleuthera, on the south-eastern tip of Eleuthera (Fig. 1). The Exuma Sound ranges in depth from 1500 to $1800 \mathrm{~m}$ and is characterised by steep walls dropping from 20 to $30 \mathrm{~m}$ to over $1000 \mathrm{~m}$ along their margins (Buchan 2000).

The waters off Cape Eleuthera were separated into 3 zones (wall zone, midbanks zone and banks zone) differentiated by coarse habitat type, water depth and distance from the pelagic waters of the Exuma Sound (Table 1). Each zone consisted of four $500 \times 500 \mathrm{~m}\left(0.25 \mathrm{~km}^{2}\right)$ sample sites $2 \mathrm{~km}$ apart and orientated approximately north-south along the long axis of the Exuma Sound (Fig. 1). These zones were sampled using both survey techniques across the 4 seasons (summer: July/August, autumn: October/November, winter: January/February, spring: April/May). Standard bait in the form of bonito tuna Euthynnus alletteratus was used for both survey types. To avoid any potential bias in the BRUVS data due to negative associations between the standardised bait and hooking during longline capture, the surveys were separated temporally. The first month of each field season was dedicated to BRUVS and the second to longline surveys.

BRUVS. Baited video units were based on the Australian Institute of Marine Science design described by Meekan et al. (2006). A mini-DV camcorder (Sony Handycam DCR-HC26) with a wide-angle adapter was enclosed in a PVC and acrylic housing (Aquatix International) and mounted on a welded steel frame (Fig. 2). A bait arm made of $25 \mathrm{~mm}$ diameter PVC pipe held a $15 \times 30 \mathrm{~cm}$ bait bag $2.5 \mathrm{~m}$ away from the front of the camera housing. The bait bag was constructed

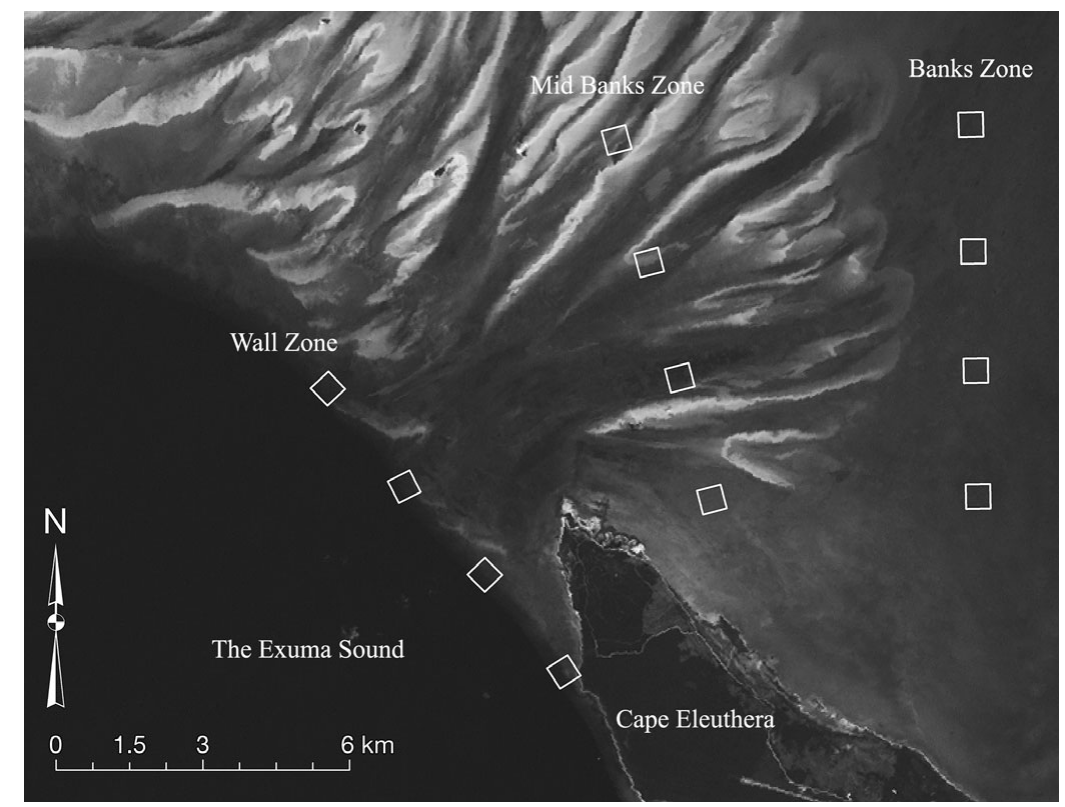

Fig. 1. Sampling zones and sampling sites (squares) in the northeast section of the Exuma Sound also showing Cape Eleuthera, The Bahamas. The dark area at the bottom left of the image represents the deep waters of the Exuma Sound, and the lighter directional shading represents shallow oolitic sand banks interspaced with deeper channels

Table 1. Key environmental characteristics of the 3 sampling zones

\begin{tabular}{|lccc|}
\hline Zone & Mean depth $(\mathrm{m})$ & Habitat description & Distance from Exuma Sound (km) \\
\hline Wall zone (WZ) & 15.3 & Coral reef, sand flats and seagrass & 0 \\
Mid-banks zone (MBZ) & 4.1 & Shallow sand banks and deep channels & 5 \\
Banks zone (BZ) & 4.3 & Seagrass, sand flats and patch reef & 12 \\
\hline
\end{tabular}




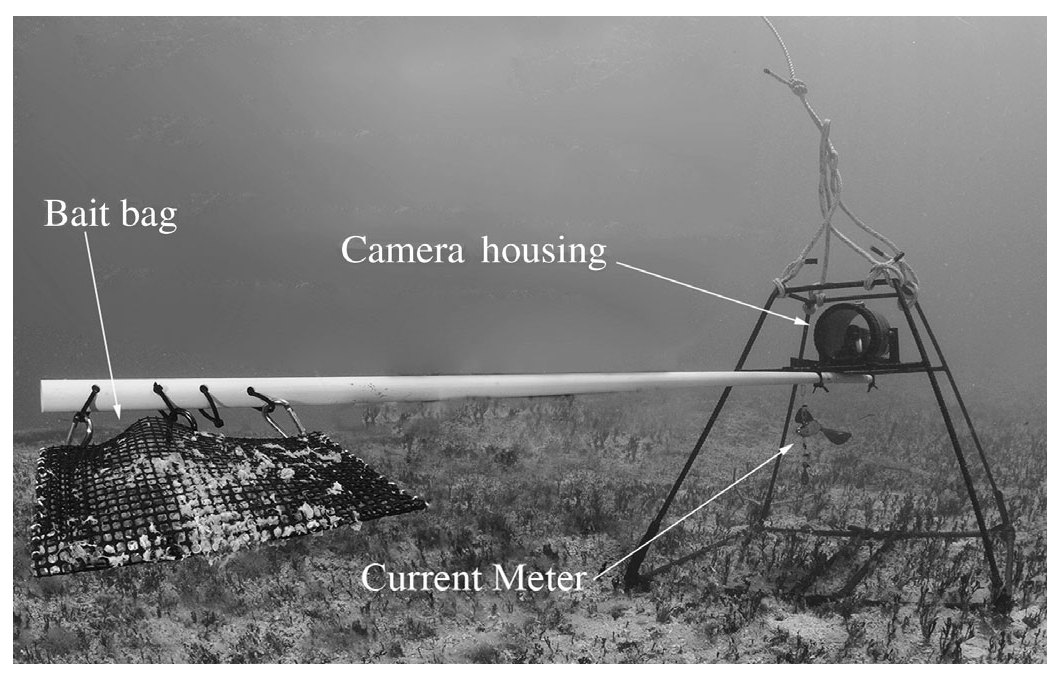

Fig. 2. Baited remote underwater video survey (BRUVS) unit deployed on the seabed

of ridged extruded plastic with a mesh size of $5 \mathrm{~mm}$ and contained $300 \mathrm{~g}$ of ground bonito tuna. A mechanical current meter (General Oceanics Model 2030 Mechanical Flowmeter) was suspended beneath the camera housing.

Units were lowered to the sea bed, and the cameras recorded continuously for a $90 \mathrm{~min}$ period. Tape recordings were analysed by at least 2 trained observers. Deployment time, species, sex and tag numbers (if applicable) were noted for any elasmobranchs caught on tape. CPUE estimates (sharks $\mathrm{h}^{-1}$ ) were derived from the deployment time and catch data.

Attempts were made to estimate the length of sharks captured on camera. A $15 \mathrm{~cm}$ scale bar was attached perpendicular to the bait arm, $1.5 \mathrm{~m}$ in front of the camera housing. A computer program (Screen Calipers, Iconico Software, www.iconico.com) for measuring the length of an object on a computer screen in relation to a known distance was used to estimate shark lengths from still frames taken from video footage. For these measurements to be made accurately, the entire shark had to be visible in the frame, near parallel to the bait arm, and no more than $1 \mathrm{~m}$ behind the scale bar (Harvey et al. 2002). These requirements were satisfied very rarely during the first 2 seasons of sampling, and attempts were discontinued for the last 2 seasons.

Longline surveys. Stationary longlines, $\sim 500 \mathrm{~m}$ in length with $\sim 35( \pm 10)$ baited gangions, were set for 90 min durations. Gangions were $2.5 \mathrm{~m}$ in length and spaced $\sim 6 \mathrm{~m}$ apart along the mainline with a support buoy attached to 2 m snoods, every 6 hooks. Each gangion ended in a 16/0, non-offset circle hook baited with a $100 \mathrm{~g}$ chunk of bonito tuna.

Due to the shallower water depths in the banks and mid-banks zones when compared to the wall zone, the longline baits were on, or within $1 \mathrm{~m}$ of, the seabed. In the wall zone, the baits were deliberately kept off the bottom due to the rugosity of the coral reef environment and the risk of entanglement for captured animals. In this area, the surveys fished from $\sim 4.5 \mathrm{~m}$ depth closest to the support buoys, to within $\sim 5 \mathrm{~m}$ of the seabed.

All sharks captured were identified to species, sexed and measured prior to release. Two external tags were deployed on all captured sharks: a 'rototag' style livestock tag attached to the upper third of the first dorsal fin (DuFlex, Destron Fearing), and a stainless steel dart tag inserted in basolateral dorsal musculature (Hallprint). For sharks hooked in the jaw, the hook was removed by cutting the barb and rotating the hook free. For sharks hooked in the throat or gut, attempts were made to remove as much of the hook and steel leader as possible prior to release. Fishing effort in hook hours was calculated by multiplying the soak time by the number of hooks set. CPUE (sharks $\mathrm{h}^{-1}$ ) was calculated from the hours of fishing effort and the catch.

Survey replication. To provide the dissimilar survey types equal opportunity to yield statistically significant results, the required sample size (n) for each technique was determined using a standard method (Harnett 1982). Data generated from a pilot study of 60 replicates conducted from July 2007 to June 2008 were used to generate minimum replicate estimates for all species encountered. The largest number of replicates indicated for a single species for a single survey was used as the minimum sample size for each survey type. Based on these calculations, the minimum numbers of replicates for BRUVS and longline surveys per sample site were set at 5 and 3 , respectively. The sampling strategy was designed to identify significant differences between sample sites within each zone. As such, the required number of replicates was conducted in each of the 4 sample sites comprising a single zone, totalling 20 BRUVS and 12 longline surveys per zone per season.

Quantitative comparisons and statistical analysis. All statistical analysis was conducted using JMP 7.0.1 (SAS Institute). Six metrics were employed to compare the results produced by longline and BRUVS techniques.

(1) Species richness and diversity. The cumulative number of individual species described over the course of the study, relative to project duration and the number of replicates, was graphically compared between 
survey types. Species richness $(S)$, or the total number of species identified by each technique, was quantified. However, given that $S$ is a non-linear function of sampling effort, absolute values of $S$ are rarely reached (Southwood \& Henderson 2000). An estimate of absolute species richness $\left(S_{\max }\right)$ was calculated from the observed species richness $\left(S_{\text {obs }}\right)$ using the Chao estimator, where $a$ is the number of species represented by single capture or sighting and $b$ is the number of species represented by 2 captures or sightings (Colwell \& Coddington 1994):

$$
S_{\max }=S_{\text {obs }}+\left(a^{2} / 2 b\right)
$$

(2) Correlation of mean CPUE values. This metric relies on the assumption that 2 equally objective survey techniques will generate relative abundance indices that are directly proportional to each other, even if the actual values generated are dissimilar. Mean CPUE for both BRUVS and longline surveys was calculated for each species, in each zone, for each season of sampling, resulting in 12 pairs of mean CPUE per species. Spearman rank correlation $(\rho)$ was used to compare resulting pairs of mean abundance indices, for all species grouped, and on a species-by-species basis.

(3) Comparisons of spatial and temporal trends in relative abundance. For 3 species of shark where a correlation was found between CPUE calculated by BRUVS and longline surveys, the effect of zone and season on shark abundance was determined using data obtained from both survey methods. A ShapiroWilk test was used to analyse the distribution of both BRUVS and longline CPUE data and in both cases was found to deviate significantly from a normal distribution, largely due to the abundance of 0 values within the data set. Therefore, Kruskal-Wallis tests were used to identify significant differences between habitat types and zones, while post hoc Mann-Whitney $U$-tests were used to further explore the data for species where significant differences were found. No Bonferroni corrections were applied, given the radical lowering of statistical power and the increased likelihood of Type II errors associated with this type of correction (Perneger 1998, Nakagawa 2004). As such, there is a $40 \%$ chance that 1 significant result in 10 could be attributed to chance (Type I error; Rice 1989).

(4) Data quality. Longline surveys provide highquality demographic and diversity data, including accurate identification of sex, species and size, all in addition to standard relative abundance estimates. During a BRUVS pilot study, it was noticed that the quality of data generated varied dependent on the behaviour of the shark in front of the camera. In some cases, the shark made a single distant pass, making it difficult to identify size, sex and occasionally species. Throughout the course of this study, the number of gaps in the BRUVS data set were recorded and compared to the longline data set.

(5) Ecological impact. The at-vessel mortality imposed by longline surveys was recorded throughout the project on a species basis. In addition, hooking location and hook retention was quantified. Negative interactions with the BRUVS equipment (e.g. bumps, entanglement) were also quantified; however, BRUVS were assumed to have no negative impact on the subject animals.

(6) Cost effectiveness. Given the tight budgets often associated with marine research projects, the financial costs of the 2 survey techniques were tracked over the course of the study and compared on a replicate, seasonal and project basis. All costs reported are location specific (e.g. local boat rental and daily wages) and were examined on a comparative basis to illustrate the relative expense of each survey type.

\section{RESULTS}

In total, 279 BRUVS and 153 longline surveys were conducted between 9 July 2008 and 9 June 2009, resulting in the capture of 112 and 372 sharks, respectively (Table 2).

Table 2. Species counts and proportional catch ratios for all shark species encountered using baited remote underwater video surveys (BRUVS) and longline surveys. Species are ranked in order of abundance during longline surveys. na: not applicable

\begin{tabular}{|lcccc|}
\hline Species & Common name & No. of longline captures & No. of BRUVS captures & BRUVS:longline \\
\hline Ginglymostoma cirratum & Nurse & 160 & 68 & $1: 2.35$ \\
Carcharhinus perezi & Caribbean reef & 115 & 26 & $1: 4.42$ \\
C. acronotus & Blacknose & 37 & 1 & $1: 37.00$ \\
Galeocerdo cuvier & Tiger & 31 & 4 & $1: 7.75$ \\
Negaprion brevirostris & Lemon & 11 & 12 & $1: 0.91$ \\
Rhizoprionodon porosus & Caribbean sharpnose & 9 & 2 & $1: 4.50$ \\
C. limbatus & Blacktip & 5 & 1 & $1: 5.00$ \\
Sphyrna mokarran & Greater hammerhead & 3 & 4 & $1: 0.75$ \\
C. leucas & Bull & 1 & 0 & na \\
\hline
\end{tabular}




\section{Species richness and diversity}

Caribbean reef Carcharhinus perezi and nurse sharks Ginglymostoma cirratum were the dominant species during both survey types, the combined catches of which comprised 83.9 and $73.9 \%$ of BRUVS and longlines, respectively. Consideration of the proportional catch rates between techniques (Table 2) suggests that on a species-byspecies basis, longlines catch between 0 and 8 times the number of individuals compared to BRUVS. The exception to this were blacknose sharks $C$. acronotus, which were caught 37 times more often during longline surveys when compared with BRUVS.

Nine different shark species were captured $\left(S_{\text {obs }}\right)$ during the longline surveys, compared to 8 species identified using BRUVS. There was a discrepancy between the efficiency of the 2 techniques in identifying the species richness of sharks in the area, with longline surveys acquiring the maximum number of species in a shorter amount of time and fewer replicates (Fig. 3). Estimates of true species richness, as generated using the Chao estimator, estimated absolute species richness $\left(S_{\max }\right)$ to be 10 for BRUVS and 9.5 for longline surveys.

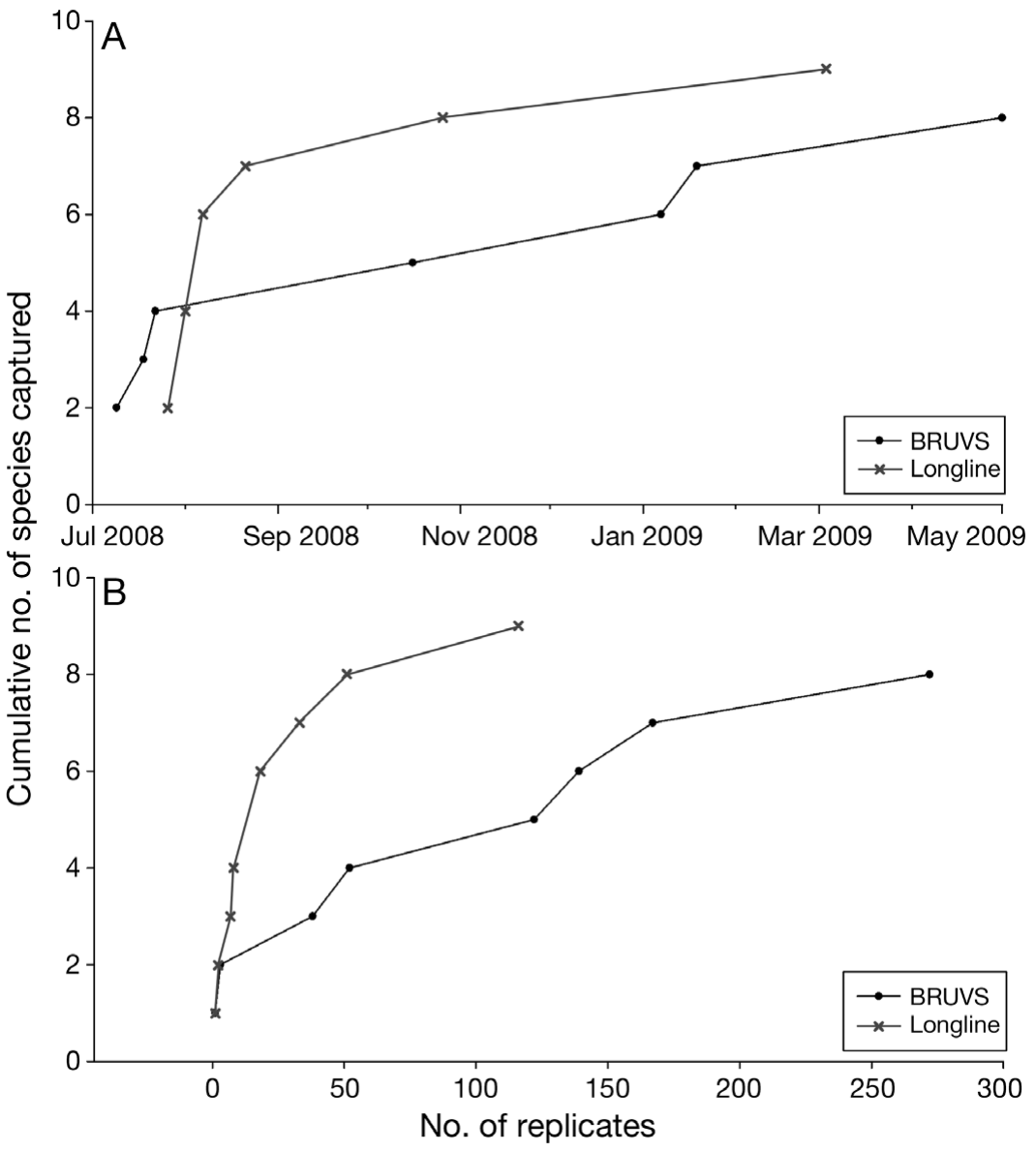

Fig. 3. Cumulative species detected by baited remote underwater video surveys (BRUVS) and longlining (A) over the course of the study and (B) by the number of replicates. Each point represents the accumulation of a new species. Plots end when the total species count is reached, illustrating the difference in time and replicate number required by each method to reach the total observed species richness

\section{CPUE}

There was a significant positive correlation $(\rho=0.80$, $\mathrm{p}<0.001$ ) between relative abundance indices generated by BRUVS and longline surveys for all species combined (Table 3). In addition, significant positive correlations of mean CPUE were found for Caribbean reef, nurse and lemon sharks. Only a single bull shark was caught on a longline and therefore no quantitative comparisons could be made between the 2 techniques. Where there was a significant correlation between CPUE calculated from longline and BRUVS data, seasonal and/or spatial differences in relative abundance were investigated in more detail.

Caribbean reef sharks (Fig. 4) were more abundant in the wall zone and decreased in abundance through the mid-banks and banks zones. This trend was replicated graphically by both surveys, although longline surveys indicated significant differences in abundance
Table 3. Spearman rank correlation $(\rho)$ of mean catch per unit effort (CPUE; sharks $\mathrm{h}^{-1}$ ) between baited remote underwater video surveys (BRUVS) and longline surveys by species, ranked in order of mean BRUVS CPUE. Statistically significant correlations $(p<0.05)$ are given in bold. na: not applicable. For Latin species names see Table 2

\begin{tabular}{|c|c|c|c|c|}
\hline Species & $\begin{array}{r}\text { Mear } \\
\text { BRUVS }\end{array}$ & $\begin{array}{l}\text { CPUE } \\
\text { Longline }\end{array}$ & $\rho$ & $\mathrm{p}$ \\
\hline Nurse & 0.2148 & 0.0116 & 0.739 & 0.006 \\
\hline Caribbean reef & 0.0812 & 0.0081 & 0.774 & 0.003 \\
\hline Lemon & 0.0351 & 0.0007 & 0.577 & 0.049 \\
\hline Tiger & 0.0129 & 0.0023 & -0.147 & 0.648 \\
\hline Greater hammerhead & 0.0116 & 0.0002 & 0.527 & 0.078 \\
\hline Caribbean sharpnose & 0.0060 & 0.0006 & 0.175 & 0.587 \\
\hline Blacknose & 0.0028 & 0.0024 & -0.195 & 0.054 \\
\hline Blacktip & 0.0027 & 0.0004 & -0.132 & 0.683 \\
\hline Bull & 0.0000 & 0.0001 & na & na \\
\hline All species & 0.1480 & 0.0099 & 0.804 & $<0.001$ \\
\hline
\end{tabular}



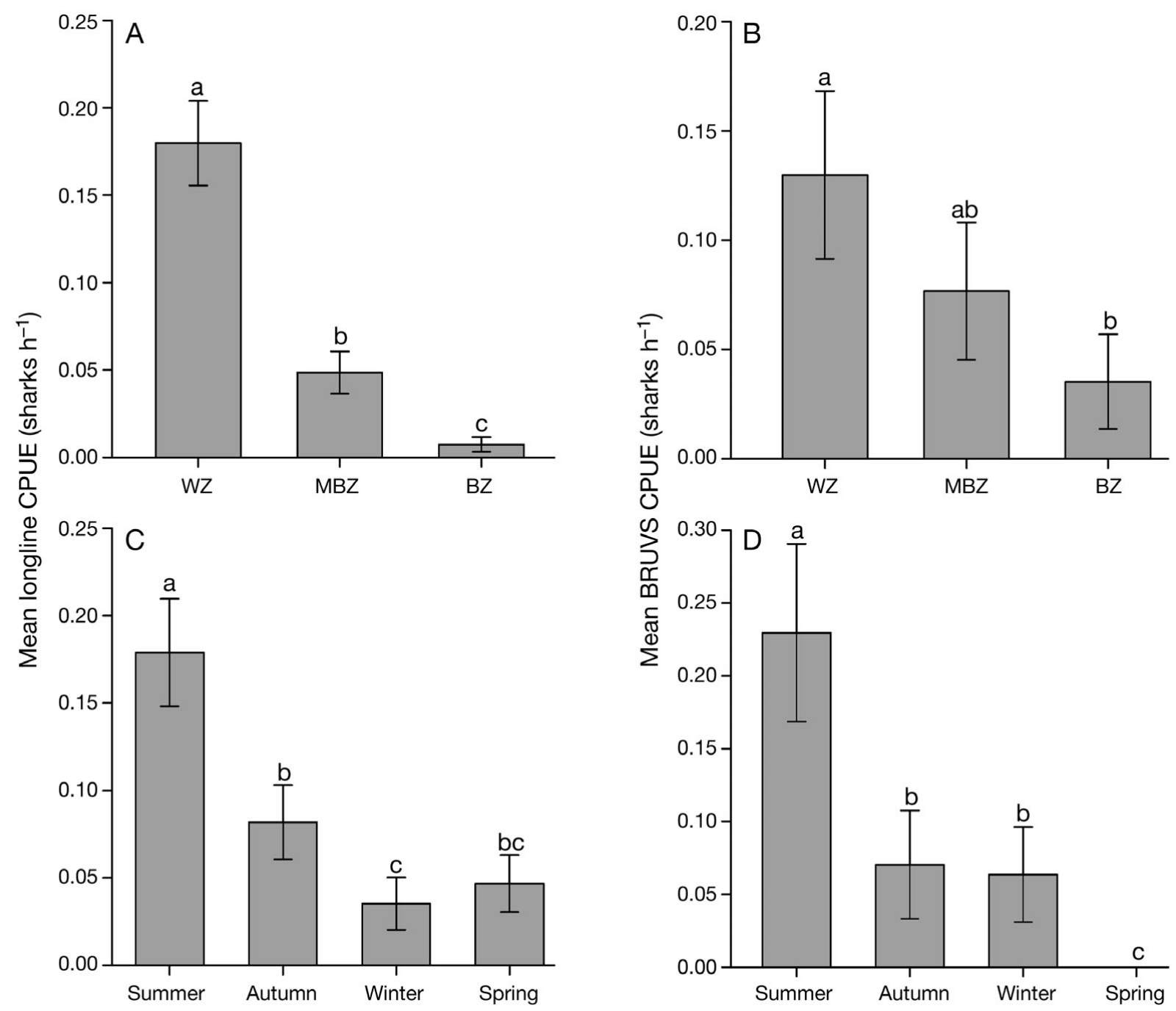

Fig. 4. Carcharhinus perezi. Relative abundance ( $\pm 1 \mathrm{SE}$ ) of Caribbean reef sharks determined by baited remote underwater video surveys (BRUVS) and longline surveys in relation to $(A, B)$ habitat zone and $(C, D)$ season. Dissimilar letters above bars signify statistically significant differences. WZ: wall zone; MBZ: mid-banks zone; BZ: banks zone

between all zones, while BRUVS only indicated a significant difference between the wall and bank zones. Caribbean reef sharks were also found to be significantly more abundant in the summer months, a trend replicated both graphically and statistically by the 2 survey techniques.

Nurse sharks were significantly more abundant in the mid-banks zone compared with both the banks and wall zones, a trend replicated both graphically and statistically by both survey techniques (Fig. 5). Both techniques showed nurse sharks to be present within the study site throughout the year, although their abundance declined in winter months. This pattern was replicated by both survey methods, but there was some variability in the statistical significance of the winter declines offered by the 2 techniques.
BRUVS indicated that lemon sharks were significantly more abundant in the winter compared with all other seasons (Fig. 6); this was not replicated by longline data, which showed no significant differences in seasonal abundance. Lemon sharks were more abundant in the mid-banks zone, but this was only significant in the BRUVS dataset.

\section{Data quality}

Longline surveys provided an assumed $100 \%$ species identification rate. Due to the variable nature of video footage obtained during baited video surveys, only $88 \%$ of 118 sharks sighted were accurately identified to species, including 14 occasions where identifi- 

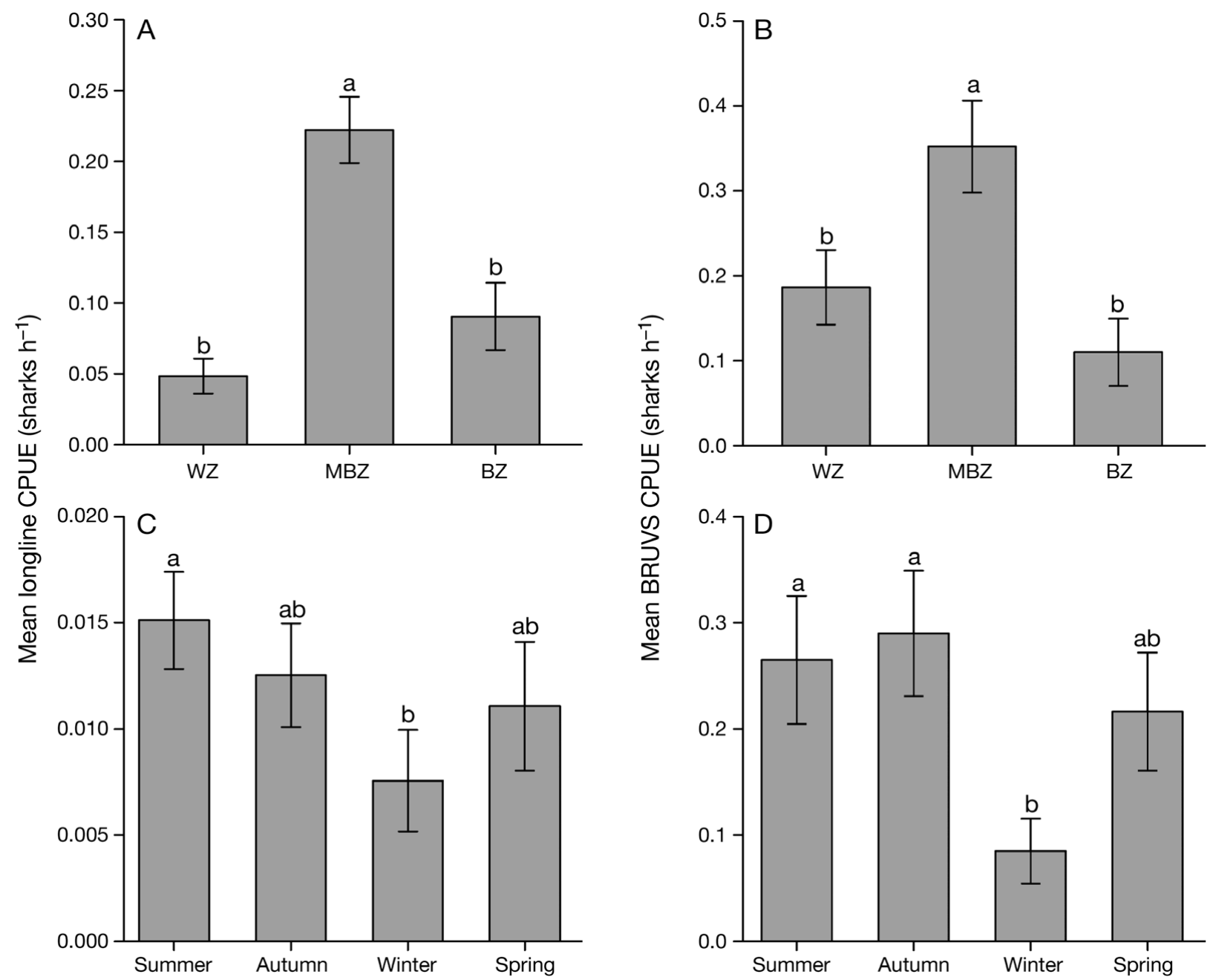

Fig. 5. Ginglymostoma cirratum. Relative abundance $( \pm 1 \mathrm{SE})$ of nurse sharks determined by baited remote underwater video surveys (BRUVS) and longline surveys in relation to $(A, B)$ habitat zone and $(C, D)$ season. Dissimilar letters above bars signify statistically significant differences. WZ: wall zone; MBZ: mid-banks zone; BZ: banks zone

cation was assigned but was determined to be questionable by the observers.

Instances of successful identification of size and sex were quantified as a percentage of the total number of sharks captured for both survey types. Longline surveys were able to determine sex in $97.8 \%$ of all sharks captured, whereas sex was only obtained from $39.8 \%$ of animals captured during baited video surveys. Accurate size measurements were obtained for $94.4 \%$ of sharks captured on longlines, whereas no accurate size measurements could be determined from baited video surveys.

\section{Ecological impact}

Longline surveys incurred an at-vessel mortality rate of $5.0 \%(n=19)$ across all species over 4 seasons of sampling for a total of 372 sharks captured. At-vessel mortality was observed in 3 of the 9 species, including $5.8 \%(\mathrm{n}=8)$ of 121 Caribbean reef sharks, $21.1 \%$ ( $\mathrm{n}=$ $8)$ of 38 blacknose sharks and $44.4 \%(n=4)$ of 9 Caribbean sharpnose sharks.

Of 339 sharks for which hooking location data existed, use of circle hooks ensured that $90.0 \%$ ( $\mathrm{n}=$ 305) were hooked in the jaw or the corner of the jaw. A further $8.8 \%(n=30)$ were hooked in the throat or the gut, and $1.2 \%(n=5)$ were hooked elsewhere on the body, usually in a pectoral fin. In some cases, it was not possible to remove the entire hook from the jaw of the shark, either due to a difficult hook placement or the need for a fast release. Of 337 sharks for which hook removal data were obtained, $18.9 \%(n=63)$ retained some part of the hook, ranging from less than $30 \%$ of the hook for difficult jaw placements, to the entire hook and a portion of the steel leader for gut- or throathooked animals. In addition, when retrieving lines, 31 gangions were encountered which had been bitten off, 

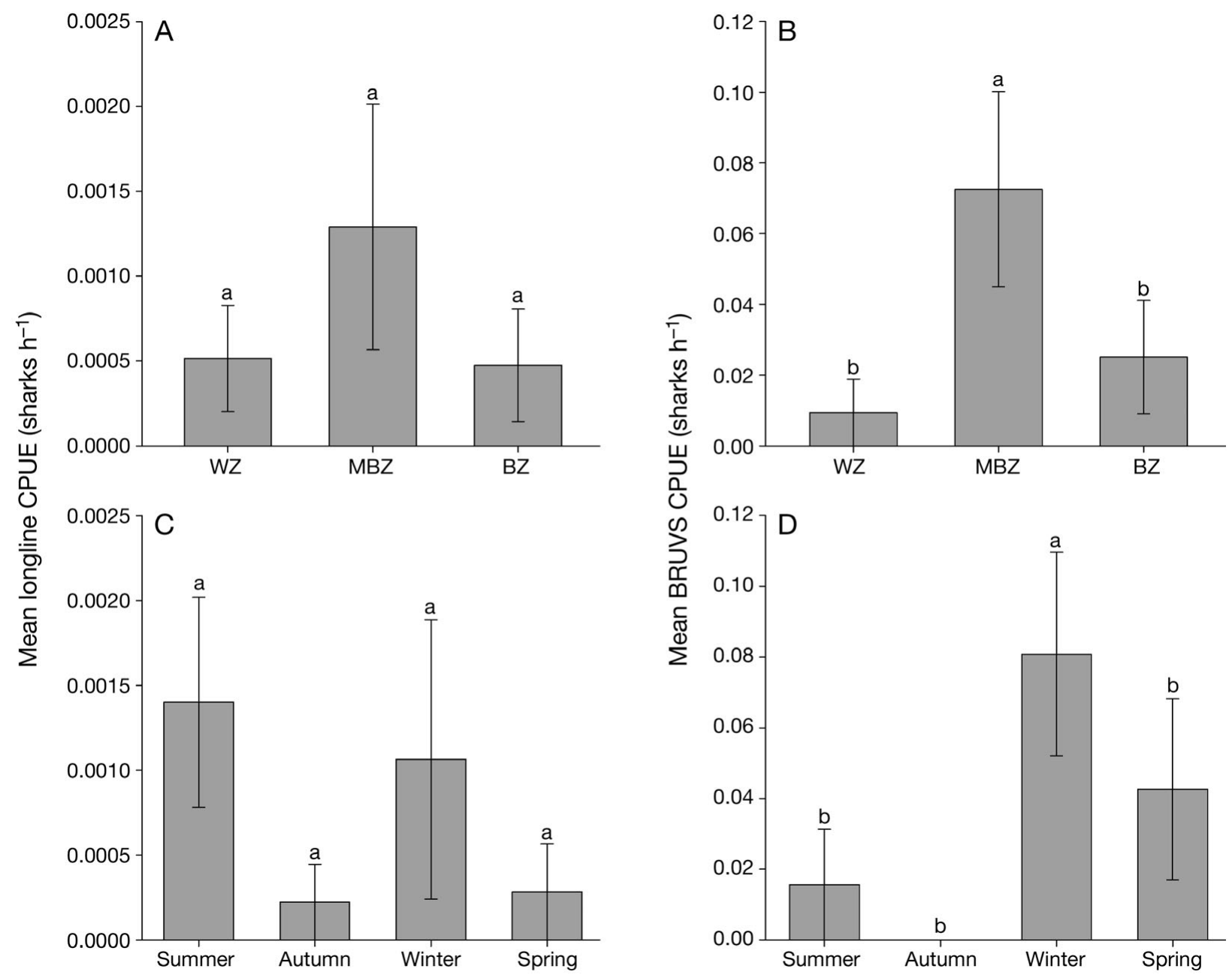

Fig. 6. Negaprion brevirostris. Relative abundance $( \pm 1 \mathrm{SE})$ of lemon sharks determined by baited remote underwater video surveys (BRUVS) and longline surveys in relation to $(A, B)$ habitat zone and $(C, D)$ season. Dissimilar letters above bars signify statistically significant differences. WZ: wall zone; MBZ: mid-banks zone; BZ: banks zone

suggesting there were additional sharks that retained hooks and a substantial portion of the gangion.

In contrast, baited videos surveys were assumed to have no impact on the surveyed sharks. Physical interactions with the units were limited to minor bumps and scrapes. On some occasions $(<20)$, units were retrieved without bait bags or bait arms - these had usually been taken by nurse sharks; however, 1 Caribbean reef shark was also observed removing the bait bag.

\section{Cost effectiveness}

The initial construction cost of 4 BRUVS units was approximately 5 times that of a single longline, and repairs and consumables costs for BRUVS over the course of the project were approximately twice those of longlines (Table 4). Despite the increased construction and maintenance costs, BRUVS showed consider- able savings over longline surveys in the long term, costing approximately one-third less over the course of the project. This was largely due to the fact that BRUVS required less boat time (35 versus $54 \mathrm{~d}$ ) and less personnel (3 versus 5 people) than longline sur-

Table 4. Relative cost breakdown for the 2 survey techniques. All values in US dollars. BRUVS: baited remote underwater video surveys

\begin{tabular}{|lrr|}
\hline & BRUVS & Longline \\
\hline Initial construction & 5500.00 & 1200.00 \\
Consumables/repairs & 1200.00 & 500.00 \\
Personnel & 6300.00 & 15300.00 \\
Boat time & 6975.00 & 10200.00 \\
Bait & 280.00 & 4150.00 \\
Total project cost & 20255.00 & 31350.00 \\
Cost per season & 5063.75 & 7837.50 \\
Cost per replicate & 72.60 & 204.90 \\
\hline
\end{tabular}


veys. The largest difference in costs was with relation to bait. BRUVS used $\sim 84 \mathrm{~kg}$ of bait over the course of the project compared to $1224 \mathrm{~kg}$ of bait used by the longline surveys.

\section{DISCUSSION}

This study suggests that BRUVS generate relative abundance and species diversity estimates similar to those generated by scientific longline surveys. Longline surveys provided an actual species richness value within 0.5 species of the theoretical maxima $\left(S_{\mathrm{obs}}=9, S_{\max }=9.5\right)$, whereas there was a 2 species difference described by BRUVS ( $\left.S_{\text {obs }}=8, S_{\max }=10\right)$. The respective survey types generated similar values of species richness $\left(S_{\text {obs }}\right)$ and similar values of estimated maximum species richness $\left(S_{\max }\right)$, although BRUVS required 5 times the number of replicates and 3 times the amount of time to reach similar values of species richness.

The highly significant correlation between the CPUE estimates generated by both survey types suggests that overall, BRUVS produce similar relative abundance estimates to longline surveys. This is in agreement with previously published research which concluded that baited video surveys can replicate the relative abundance indices generated by longline surveys for juvenile pink snapper in Hawaii (Ellis \& DeMartini 1995). However, this multi-species correlation masks the potential influence of individual species abundance on the comparability of the 2 techniques. On a species-by-species basis, significant correlations occurred for only 3 of the 8 species encountered during both survey types; these represent the 3 most commonly encountered species in the BRUVS (Table 3).

The lack of correlation between the survey techniques for the less abundant species suggests a threshold level of CPUE below which data from BRUVS no longer match those obtained by longline surveys. This idea is further supported by a more detailed analysis of the graphical and statistical agreement between the 2 techniques. The 2 most abundant species, Caribbean reef and nurse sharks, had very clear graphical trends (Figs. 4 \& 5), and the statistical significance of these trends was well replicated by the 2 techniques. The less abundant lemon shark (Fig. 6) had clear spatial trends described by both techniques, although they varied in the degree of statistical significance between techniques. In addition, there were conflicting patterns in seasonal abundance described by the respective survey techniques, and the statistics which supported them were contradictory. For this study, it appears that the threshold of statistical agreement between the 2 techniques is approximately that of the mean CPUE of lemon sharks $\left(0.0351\right.$ sharks $\left.\mathrm{h}^{-1}\right)$ obtained by BRUVS.
Relative abundance values calculated from BRUVS for species with a mean CPUE less than that of lemon sharks should be treated cautiously. Absolute values of relative abundance will vary between studies according to the number of replicates and the variety of habitats from which these replicates were derived. However, if these variables were standardised, then direct comparisons to the figures generated over the course of this study could be made.

The overarching issue with BRUVS is one of data quality, the most fundamental component of which is accurate species identification. The carcharhinid family, to which 7 of the 9 species encountered in this study belong, are difficult to identify due to similar body types, colouration and markings (Grace 2001). These identifications are difficult even when the shark is secured adjacent to a boat following longline capture and fine-scale morphological differences can be identified (e.g. presence or absence of an inter-dorsal ridge). The problem is exacerbated during BRUVS due to the variable behaviour of sharks in front of the camera, leading to variable video footage. Indeed, only $88 \%$ of sharks captured in BRUVS were accurately identified to species because on many occasions the animals did not approach the camera.

Frequent misidentification of blacknose sharks during the analysis of the BRUVS could account for the anomaly in the proportional catch rates between techniques. Longlines captured between 0 and 8 times the number of individuals when compared with BRUVS for all species other than blacknose sharks, which were caught 37 times as often (Table 2). Blacknose sharks are among the more difficult species to identify, as they are morphologically very similar to Caribbean reef and Caribbean sharpnose sharks, and are present in an overlapping range of sizes. It is likely that blacknose sharks, and potentially Caribbean sharpnose sharks, were often misidentified as small Caribbean reef sharks during BRUVS. It is interesting to note that spatial relative abundance trends in Caribbean reef sharks were less statistically defined in BRUVS than in longline surveys, a potential artefact of erroneously classing a blacknose as a Caribbean reef shark. Longline data suggest that blacknose sharks are more evenly distributed throughout the 3 habitat zones (data not shown) than the Caribbean reef shark, which would account for the less statistically defined spatial trends described by BRUVS. Longline data also suggested that blacknose sharks are more abundant in the summer, which coincides with the increase of Caribbean reef shark abundance and accounts for the lack of dilution in the seasonal trends.

In addition to the issues with species identification during BRUVS, sex could only be established in less than $40 \%$ of the sharks captured. Size could not be 
estimated using the BRUVS in the configuration used in this study, although this problem would be easily rectified by incorporating the stereo-video techniques described in contemporary baited-video literature (e.g. Harvey et al. 2002, 2003). Conversely, longline surveys yielded species, sex and size on nearly all occasions, allowing CPUE estimates to be generated for demographics within a species, above and beyond overall species abundance. Given the sexual and ontogenetic segregation prevalent in a number of shark species (Mucientes et al. 2009), there is a need for survey techniques to provide relative abundance data at an intraspecies resolution, dependent on the scale of the question being approached. This is beyond the technical capability of the BRUVS units and protocols tested in this study, although it is potentially possible with the incorporation of the aforementioned stereo-video techniques to provide length estimates. It is also possible that the inclusion of contemporary stereo-video techniques might improve the identification of sex and could potentially aid in species identification by providing quantitative data on key morphological characteristics such as insertion of the first dorsal fin relative to the axial and inner margin of the pectoral fin, a critical identifier for many carcharhinid species. Furthermore, the mini-DV cameras used in this study are reliant on digital video technology which is several years out of date. The incorporation of more modern high-definition digital video cameras could potentially improve the rates of identification for both species and sex (Harvey et al. 2010).

Efforts were made to ensure that longline surveys incurred the least amount of ecological impact possible for a capture-based survey method. At-vessel mortality rates of $5 \%$ for longline surveys were less than those experienced during similar surveys in Belize, which ranged from 6 to $7 \%$ (Pikitch et al. 2005, D. Chapman pers. comm.) The circle hooks worked well to ensure that the majority $(90 \%)$ of sharks were hooked in the jaw and relatively few sharks retained any part of the survey hardware. Despite the care taken to minimise the impact of the longline surveys, mortality did occur. In addition, the levels of post-release mortality are unknown, although the results of an acoustic telemetry study focusing on Caribbean reef sharks suggest that the majority of captured animals do survive and return to normal behavioural function after $\sim 6 \mathrm{~h}$ (E. Brooks unpubl. data).

Longline surveys are more resource intensive to run than BRUVS, and are therefore less cost effective. BRUVS accrued approximately two-thirds the costs of the longline surveys over the course of the project. The major costs for BRUVS are initial equipment costs and occasional replacement of water-damaged cameras, whereas personnel, bait and boat costs are far lower than for longline surveys. Once BRUVS units have been constructed, long-term monitoring with this technique is more cost effective than with longline surveys. The addition of more expensive high definition cameras and more advanced stereo-video techniques would add to the initial construction costs of BRUVS but would likely still be more cost effective over the course of a long-term project.

In addition to the financial costs of bait, another important consideration is the ecological cost of removing large volumes of wild-caught fish from the marine environment. Over the course of the project, longline surveys consumed $92.1 \%$ more bait than BRUVS, requiring over $1000 \mathrm{~kg}$ of wild-caught bonito tuna at an unknown environmental cost. We concede that both the environmental and ecological costs of bait can be mitigated to a certain degree by using waste fish (e.g. carcasses from fish docks and marinas), although if any effort is to be made to standardise bait across seasons and locations, commercially purchased fish is the only viable option.

In conclusion, BRUVS are a viable, less invasive and more cost-effective alternative to longline surveys depending on the specific research question being approached. They are especially suited for long-term monitoring of species richness and relative abundance over wide geographical and temporal scales, as they are easily replicated by relatively untrained personnel without specialised equipment. However, the BRUVS tested in this project lacked the resolution required to approach finer-scale ecological questions, which would be better approached with longline surveys. Longlines, if structured correctly, provide a higher quality data set with the added benefit of acting as a vehicle for conventional tagging, or deploying and retrieving a suite of biotelemetry devices. Longlines, even those run in the most benign manner possible, will still incur mortality; however, the ethical debate required to define an acceptable level of mortality to better understand and protect a species is outside the scope of this study. An experimental design which incorporates long-term BRUVS sampling and discrete, temporally stratified periods of longline sampling can provide the benefits of both techniques.

Acknowledgements. We thank A. Oronti, A. Shultz, R. Ormond and J. Stein for their support and feedback throughout the course of this study and the development of this manuscript. Field support was provided by numerous hard working volunteers, including C. Berry, J. Wilchcombe, A. Vellacott, B. Maxey, N. Weeden, J. Spät, G. Nanninga, K. Sherman, M. Anderson, C. Booker, L. Hassan-Hassanein and J. Searle. Thanks also to the Island School students of 2007 and 2008 who provided invaluable field support, and to R. Velardo for supporting their endeavours. Special thanks to G. Walton and J. Shultz for fabricating the frames for the BRUVS housing, 
and to J. Morris and R. Heuter of Mote Marine Laboratory for their support, advice and training while developing our longline surveys. This work would not have been possible without the financial support of the Save Our Seas Foundation and the Cape Eleuthera Foundation.

\section{LITERATURE CITED}

Armstrong J, Bagley P, Priede I (1992) Photographic and acoustic tracking observations of the behaviour of the grenadier Coryphaenoides (Nematonurus) armatus, the eel Synaphobranchus bathybius, and other abyssal demersal fish in the North Atlantic Ocean. Mar Biol 112: 535-544

Bailey DM, King NJ, Priede IG (2007) Cameras and carcasses: historical and current methods for using artificial food falls to study deep-water animals. Mar Ecol Prog Ser 350:179-191

Baum J, Myers R (2004) Shifting baselines and the decline of pelagic sharks in the Gulf of Mexico. Ecol Lett 7:135-145

Baum J, Myers R, Kehler D, Worm B, Harley S, Doherty P (2003) Collapse and conservation of shark populations in the northwest Atlantic. Science 299:389-392

Buchan K (2000) The Bahamas. Mar Pollut Bull 41:94-111

Cappo M, Speare P, De'ath G (2004) Comparison of baited remote underwater video stations (BRUVS) and prawn (shrimp) trawls for assessments of fish biodiversity in interreefal areas of the Great Barrier Reef Marine Park. J Exp Mar Biol Ecol 302:123-152

Cappo M, Harvey E, Shortis M (2006) Counting and measuring fish with baited video - an overview. In: Lyle JM, Furlani DM, Buxton CD (eds) Cutting-edge technologies in fish and fisheries science. Australian Society for Fish Biology Workshop. Australian Society of Fish Biology, Hobart, p 101-115

Colwell R, Coddington J (1994) Estimating terrestrial biodiversity through extrapolation. Philos Trans R Soc Lond B Biol Sci 345:101-118

Cooke S, Schreer J, Dunmall K, Philipp D (2002) Strategies for quantifying sublethal effects of marine catch and release angling: insights from novel freshwater applications. Am Fish Soc Symp 30:121-134

Ellis D, DeMartini E (1995) Evaluation of a video camera technique for indexing abundances of juvenile pink snapper, Pristipomoides filamentosus, and other Hawaiian insular shelf fishes. Fish Bull 93:67-77

Field I, Meekan M, Buckworth R, Bradshaw C (2009) Susceptibility of sharks, rays and chimaeras to global extinction. In: Sims DW (ed) Advances in marine biology Vol 56. Elsevier, Cambridge, p 275-363

Garla R, Chapman D, Shivji M, Wetherbee B, Amorim A (2006) Habitat of juvenile Caribbean reef sharks, Carcharhinus perezi, at two oceanic insular marine protected areas in the south-western Atlantic Ocean: Fernando de Noronha Archipelago and Atol das Rocas, Brazil. Fish Res 81:236-241

Grace M (2001) Field guide to requiem sharks (Elasmobranchiomorphi: Carcharhinidae) of the western North Atlantic. NOAA Tech Rep NMFS 153. US Dept Commerce, Seattle, WA

Harnett D (1982) Statistical methods. Addison-Wesley Publishers, Reading, MA

> Harvey E, Shortis M, Stadler M, Cappo M (2002) A comparison of the accuracy and precision of measurements from single and stereo-video systems. Mar Technol Soc J 36: $38-49$
Harvey E, Cappo M, Shortis R, Robson S, Buchanan J, Speare P (2003) The accuracy and precision of underwater measurements of length and maximum body depth of southern bluefin tuna (Thunnus maccoyii) with a stereo-video camera system. Fish Res 63:315-326

> Harvey E, Goetze J, McLaren B, Langlois T, Shortis M (2010) The influence of range, angle of view, image resolution and image compression on underwater stereo-video measurements: high definition and broadcast resolution video cameras compared. Mar Technol Soc J 44:75-85

> Heithaus M, Wirsing A, Dill L, Heithaus L (2007) Long-term movements of tiger sharks satellite-tagged in Shark Bay, Western Australia. Mar Biol 151:1455-1461

Henderson P (2003) Practical methods in ecology. Blackwell Science, Oxford

> Holland K, Wetherbee B, Lowe C, Meyer C (1999) Movements of tiger sharks (Galeocerdo cuvier) in coastal Hawaiian waters. Mar Biol 134:665-673

Isaacs J (1969) The nature of oceanic life. Sci Am 221:146-162

IUCN (2010) Red List of Threatened Species. Available at www.iucnredlist.org (accessed on 2 Sep 2010)

> Malcolm HA, Gladstone W, Lindfield S, Wraith J, Lynch TP (2007) Spatial and temporal variation in reef fish assemblages of marine parks in New South Wales, Australiabaited video observations. Mar Ecol Prog Ser 350:277-290

Meekan M, Cappo M (2004) Non-destructive techniques for the rapid assessment of shark abundance in Northern Australia. Report prepared for the Department of Agriculture Fisheries and Forestry. Australian Institute of Marine Science, Townsville

Meekan M, Cappo M, Carleton J, Marriott R (2006) Surveys of sharks and fin-fish abundance on reefs within the MOU74 Box and Rowley Shoals using baited remote underwater video systems. Report prepared for the Department of the Environment and Heritage. Australian Institute of Marine Science, Townsville

Mucientes G, Queiroz N, Sousa L, Tarroso P, Sims D (2009) Sexual segregation of pelagic sharks and the potential threat from fisheries. Biol Lett 5:156-159

Myers R, Baum J, Shepherd T, Powers S, Peterson C (2007) Cascading effects of the loss of apex predatory sharks from a coastal ocean. Science 315:1846-1850

> Nakagawa S (2004) A farewell to Bonferroni: the problems of low statistical power and publication bias. Behav Ecol 15: $1044-1045$

> Perneger T (1998) What's wrong with Bonferroni adjustments? BMJ 316:1236-1238

> Pikitch EK, Chapman DD, Babcock EA, Shivji MS (2005) Habitat use and demographic population structure of elasmobranchs at a Caribbean atoll (Glover's Reef, Belize). Mar Ecol Prog Ser 302:187-197

Priede I, Merrett N (1996) Estimation of abundance of abyssal demersal fishes: a comparison of data from trawls and baited cameras. J Fish Biol 49:207-216

Rice W (1989) Analyzing tables of statistical tests. Evolution 43:223-225

$>$ Rollin BE, Kessel ML (1998) Guidelines for the treatment of animals in behavioural research and teaching. Anim Behav 55:251-257

Shortis M, Harvey E, Abdo D (2009) A review of underwater stereo-image measurement for marine biology and ecology applications. Oceanogr Mar Biol Annu Rev 47: 257-292

> Simpfendorfer C, Hueter R, Bergman U, Connett S (2002) Results of a fishery-independent survey for pelagic sharks in the western North Atlantic, 1977-1994. Fish Res 55: 175-192 
Skomal G (2006) The physiological effects of capture stress on post-release survivorship of sharks, tunas and marlin. PhD dissertation, Boston University, Boston, MA

Skomal G (2007) Evaluating the physiological and physical consequences of capture on post release survivorship in large pelagic fishes. Fish Manag Ecol 14:81-89

Southwood T, Henderson P (2000) Ecological methods. Blackwell Science, Oxford

Stevens J, Bonfil R, Dulvy N, Walker P (2000) The effects of fishing on sharks, rays, and chimaeras (chondrichthyans),

Editorial responsibility: Brendan Godley,

University of Exeter, Cornwall Campus, UK and the implications for marine ecosystems. ICES J Mar Sci 57:476-494

Willis TJ, Millar RB, Babcock RC (2000) Detection of spatial variability in relative density of fishes: comparison of visual census, angling, and baited underwater video. Mar Ecol Prog Ser 198:249-260

Wirsing A, Heithaus M, Dill L (2006) Tiger shark (Galeocerdo cuvier) abundance and growth in a subtropical embayment: evidence from 7 years of standardized fishing effort. Mar Biol 149:961-968

Submitted: October 28, 2010; Accepted: December 31, 2010 Proofs received from author(s): March 2, 2011 